\title{
The Mechanism of Border Crossings' Economic Impact on the City Under Geopolitical Factors
}

\author{
MA Yihui \\ School of Economics and Management, Beijing Jiaotong University, BeiJing, China 100044 \\ myihui@163.com
}

\begin{abstract}
Keywords: Border crossings, Geo Economics, Frontier trade theory, Cline's national evaluation
\end{abstract} model

\begin{abstract}
Border crossing which is set up in adjacent border areas as main door of foreign exchanges by a sovereign state according to the policy needs. due to the unique geographical location and rich natural resources, Border crossings have very important strategic position in the economic development of China. Under the trend of the geopolitical structure services economic interests, border city with border crossings has become an important basis for the development of border economy in "One Belt And One Road"It is very urgent for us to solve the problem of how to promote border economic development from the perspective of Geo economics, Frontier trade theory. The paper explains the mechanism of interaction of border crossings, geopolitical factors for city economic development from the perspective of Geo economics, and then uses Cline's national evaluation model which analysis the impact of geopolitical factors and different modes of transportation, highway border crossing, railway border crossing port border crossing on the border city's economy, which considers the particularity of border crossing's economy development. The research has practical significance and theoretical significance for border city to seize the opportunity of geopolitical development strategy in the future.
\end{abstract}

\section{Introduction}

As one of the main doors between different countries,border crossings have a great impact on national economic development of border city. By the end of 2014, China opens 288 ports , 20 railway crossings, with 12 in the border area. By combing the development history of railway ports in China, we can find that the establishment of railway ports is directly related to the geographical factors of neighboring countries. In addition, China opens 67 road crossings, with 57 located in the border area, 135 ports, with 35 located in the border area. The opening of highway crossing and ports is mostly related to the geopolitical environment of neighboring countries. The crossing's economic becomes a mirror reflection of the bilateral relations.

Under the trend of the geopolitical structure services economic interests, border city with border crossings has become an important basis for the development of border economy in "One Belt And One Road". The paper focus on explaining why the international environment has an important role for the border city economic development? How about the main pathways and mechanisms identified? Based on Cline's national evaluation model the paper analysis the impact of geopolitical factors and different modes of transportation, highway border crossing, railway border crossing port border crossing on the border city's economy, which considers the particularity of border crossing's economy development and comprehensive use Geo economics and Border trade theory complement and develop the existing research deficiencies.

\section{The Particularity of Border Crossing's Economy}

Port is the station for personnel, goods and vehicles to the entry and exit.Border crossing which is set up in adjacent border areas as main door of foreign exchanges by a sovereign state according to the policy needs. In accordance with the local port, all the port can be divided into coastal areas,inland areas,along the border which include 8 provinces:Heilongjiang, Jilin, Liaoning, Inner Mongolia, 
Xinjiang, Tibet, Yunnan, Guangxi (autonomous region). The border economy is based on the port as the core, directly or indirectly, relying on the border crossing to develop the trade, processing, warehousing, economic and technical cooperation, tourism, shopping, financial services, infrastructure construction, cross industry, cross regional, multilevel complex economy.

Most border crossings in China are located in "old, little, edge, poor" areas,distribute in the border between China and Russia, Kazakhstan and Mongolia,North Korea,little in Pakistan, Kyrgyzstan, India, Nigeria.At present, the new economic situation puts forward new requirements for Chinese border crossing economic development. So when make development policies and measures for border crossings, we should be fully aware of the particularity of border economy.

Border crossings are highly sensitive to bilateral relations and dependent geopolitical neighbors. Border crossings in the transition point of bilateral sovereignty, are sensitive to changes in bilateral relations in political, diplomatic, military. Border economy directly reflects the bilateral relations. Railway, highway and a small river are the main traffic for border and the mainland border crossings with neighboring ports designated correspondence as"one to one" in trade partners. The prosperity of the other ports will promote the foreign trade and economic exchanges at the corresponding ports. Similarly, the decline of one port often involves the corresponding ports.

\section{Theoretical Background}

Geo economics is a comprehensive study on the geographical space and historical culture, system of organization, national psychology, political relations and other geopolitical factors and national or regional foreign behavior relationship,and national and regional economic behavior and political behavior economic purpose as the main object of study. From the perspective of geopolitical relations between countries to promote economic cooperation between different ethnic groups, countries, has the practical significance.Some scholars such as Zhang Lijun (2000), Lu Guangsheng (2004), think that Geo economics as a branch of the theory of international relations conforms to the national requirements for the new historical period and is very important for international relations, world pattern. Pan Zhongqi (2008) from the connotation and extension of geo economics, China geopolitical strategy includes: economic strategy, geopolitical strategy and culture strategy.

Border trade happens between different sovereign states in the border areas to the exchange of commodity and non commodity economy cooperation activities.Because border trade has a specific range and boundaries, it is a special manifestation of international trade, foreign trade and inter regional trade. Border trade must be in the adjacent countries between the border areas, the scale and form of trade also have some restrictions, the development of border trade often promote the development of related industries such as translation, finance, transportation etc. Therefore, frontier trade clearly embodies the basic attributes of regional and comprehensive geography.

\section{The Mechanism of the Development of Border City}

(1)Micro macro analysis of Geo economy. Geo economics is a product of the trend of the times, and mainly use the power and the law of economic for global competition, to seek the dominate position in the world economic system and world political system.According to the theory of Geo economics, border area is the best location for developing border trade. The neighboring border area have the social basis of the development of border trade, including similar geographical environment, border similar or the same language, culture, habits and religious beliefs. The differences in the economic and social development of neighboring border areas have become the driving force for the interdependence and mutual complement between the border regions. Therefore, in the era of Geo economy, neighboring countries should make full use of the advantages of border adjacent to jointly promote each others economic development, to achieve the maximization of national economic interests is the fundamental.

In addition, due to the occurrence of border trade must be conducted in the adjacent countries in border areas, which greatly influence the development of border city.From the Micro view Geo 
economic will directly effect economic development of countries in the border areas,opening doors is take each corresponding port for direct contact, so we can study the border city development as the direct manifestation of Geo economics.

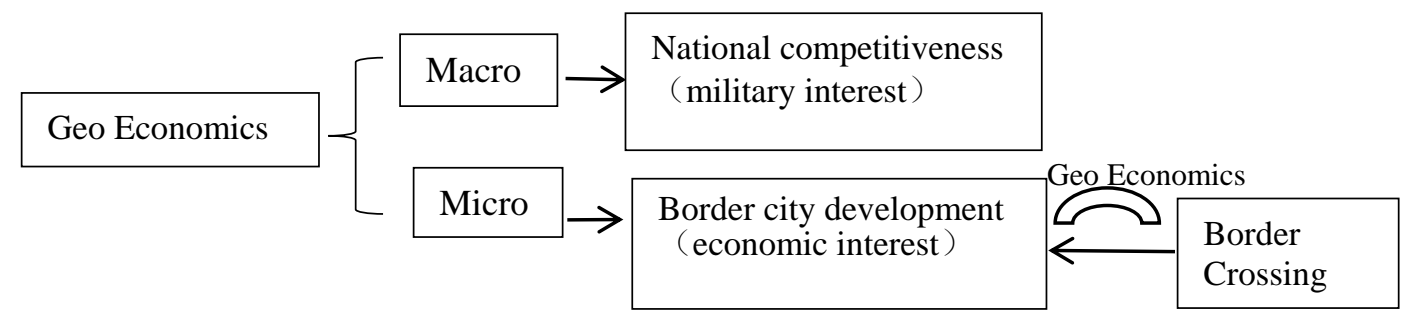

Fig1.Macro and Micro perspective of Geo Economics

Due to the Macro geopolitical economic impact changes by political factors obviously, this paper is mainly analyze the border Geo economics development from micro angle.

(2)The interaction between geographical factors and border crossings economy. A country's geopolitical factors will have an important impact on national development, economic behavior and strategic choice. In the Geo economic era, the connected state is focus on developing economy through regional cooperation to reduce the influence of the boundary on the economic cooperation between countries. The border crossing is a reflection of Geo economic effect. The development of border economy promotes economic development and bilateral cooperation in various countries, which is conducive to the development of a peaceful and stable surrounding environment, is conducive to positive interaction in international relations, to guarantee the national security. Therefore, the rapid development of border economy is conducive to the stable development of Geo relations.Security as the core elements of the development of international relations, the border city should consider both their own vulnerability and external security threats to the country.Geopolitical factors, border economy and security issues interact in the development of border city.

\section{Model of Mechanism}

\section{(1)Cline's national evaluation model:}

$P_{p}=(C+E+M) \times(S+W)$

$\operatorname{PP}($ National Power),C(Critical Mass),E(Economic Capability),M(Military Capability),S(Strategic Purpose),W(Will to Pursue National Strategy).In order to further refine the scope of research in urban scope, firstly, the explanatory variables and the explanatory variables are replaced.

Because of the border city belong to export-oriented economic and trade is main part,so in order to highlight the particularity of the border economy, we can set the trade development as the border city economy.Because the economic contact of air crossing is mostly "one to many" form, the dependence of neighboring countries is not significant, So this paper only studies the railway crossing, highway crossing,port import and export development.this paper only use different modes of transportation port of import and export in one area proportion index as explanatory variables.

\section{(2)Evaluate the railway crossing effect on border city development:}

$G e o P E_{i}=\left(B_{i}+C_{i}+D_{i}+E_{i}+F_{i}\right) \times\left(\alpha S_{j}+\beta W_{i j}\right)$

$G e o P E_{i}$ :border city impact in area i, $B_{i}$ :Export growth rate in area i, $C_{i}$ :Proportion of export of railway port to total area $\mathrm{i}, D_{i}$ :Import and export balance index in area $\mathrm{i}, E_{i}$ :Regional export diversification index in area $\mathrm{i}, F_{i}$ :Inter country trade competition index, Find out the first three of the export area and export volume of each country, if the export area $i$ same then quantity addition divided by country exports, $\alpha$ :Number of countries along the border crossing, $S_{j}$ :Geo export strategic index of port exporting countries $\mathrm{j}, \beta$ :Economic strength proportion of the region $\mathrm{i}$ to total area, $W_{i j}$ :The relationship between the two countries $\mathrm{i}, \mathrm{j}$, by the international relations event analysis. 
The other highway crossing, port of border areas evaluation model reference model of railway crossing.

\section{Summary}

Border crossings due to the special geographical location has high sensitivity and geopolitical dependence. At present, the research on border crossings is mostly focused on the internal economic research, and it lacks the analysis of the influence of geographical factors on the economic development of border crossing from the whole world environment. In this paper, Cline's national strength evaluation model is used to by reassigning the meaning of variables study the influence of geographical privacy on border economy. Secondly, the paper study the impact of different types of border economy of border city, this model has a certain reference value for future research on the reasonable economic interpretation of the port layout. The main innovation of this paper is the qualitative analysis of the influence mechanism among border crossing, Geo factors and urban economic development. Although the border port located in the "old, little, edge, poor" border area, but its economic advantage is very outstanding. Under the background of economic globalization and the "One Belt and One Road",economic development of border area has a certain strategic significance.

\section{Acknowledgements}

This work was financially supported by the General Project of National Social Science Fund, (15BTJ003).

\section{References}

[1] China Port Association Editor. China port Yearbook [M]. Chinese Customs Press, 2015

[2] Hu Zhiding, Liu Weidong, Song Tao. Consensus between the main body,geopolitical structure to build"One Belt and One Road"[J].Tropical Geography, 2015,35 (5): 621-627

[3] Liu Jianli. China's border particularity analysis and suggestions for the development [J]. China Business and Market. 2011 (12): 45-49

[4] Li Dunrui, Li Xin. Geo economics review [J]. Social Sciences Abroad, 2009 (1): 42-48.

[5] Zhang Lijun. Geo Economics: an introduction to the national economy from the geo economic [M]. Beijing: China Three Gorges press, 2000

[6] Lu Guangsheng. Study geo economics in international relations [J] World Economy Study , 2004 (3):11-16.

[7] Pan Zhongqi, Huang Renwei. Chinese geo economic strategy [J]. Journal of Tsinghua University(Philosophy and Social Sciences). 2008 (5): 116-122.

[8] Chi Qinglin. the border trade and economic development [D]. Beijing: Graduate School of China Academy of Social Sciences, 2001

[9] Zhang Lijun, Wang Yufen. The building of a harmonious society in ethnic minority areas and border trade development [M]. Beijing: China economic press, 2008:82-210

[10] Li Qin, Xu Yunxia, the Development of export-oriented economy in the border areas of China [J]. China Opening Herald. 2009 (6): 64-67 